\title{
Psychodynamic approaches to suicide and self-harm ${ }^{\dagger}$
}

\author{
Jessica Yakeley \& William Burbridge-James
}

\begin{abstract}
SUMMARY
Rates of suicide and self-harm are rising in many countries, and it is therapeutically important to explore the personal stories and relationships that underlie this behaviour. In this article psychoanalytic and psychodynamic principles and concepts in relation to violence towards the self are introduced and the various unconscious meanings of suicide and self-harm are explored within a relational context and attachment framework. We describe how a psychodynamic approach may enhance the risk assessment and treatment of patients presenting with self-harm and suicidality, particularly examining the role of transference and countertransference within the therapeutic relationship.
\end{abstract}

\section{LEARNING OBJECTIVES}

- Understand historical and contemporary psychoanalytic theories and concepts regarding the aetiology of suicide and self-harm

- Understand the different meanings and expressions of acts of suicide and self-harm

- Understand the use of countertransference in the risk assessment and management of selfharm and suicide attempts

\section{DECLARATION OF INTEREST}

None.

The prevention of suicide and self-harm has been high on the government's agenda for the past 15 years. Although statistics and demographics are essential in identifying preventive measures or high-risk groups for targeted interventions, they may also overshadow exploration of the myriad individual stories and relationships that lie behind each act of self-harm or suicide.

Suicide and self-harm are acts of human behaviour that take us to the limits of our comprehension. Contemporary debates as to whether the causes of suicide are located within the individual or society stem from the early seminal works of Freud (1917) and Durkheim (1897) respectively. Since then, many theoretical frameworks have emerged that offer different conceptualisations and understandings of the causes, associated factors and effects of self-harm and suicidal behaviour. These include sociological approaches evolving from Durkheim's work on the role of social control to contemporary notions of deviance, stigmatisation and self-expression (Taylor 2015); cultural approaches examining how suicide and self-harm vary across gender, ethnicity, sexual orientation and other cultural characteristics (Cover 2016); and philosophical and ethical approaches exploring notions of utilitarianism, autonomy and duty to others (Kelly 2011). More recent psychopathological models include biological approaches studying the neurobiological correlates of self-injurious behaviour (Blasco-Fontecilla 2016) and contemporary psychological approaches that have informed the development of effective therapeutic interventions. All of these models overlap to some extent, for example many viewing self-harm as an expression of emotional distress.

A psychodynamic perspective on self-harm and suicidal behaviour is one approach that may complement others in its focus on affective experience, unconscious meaning and interpretation within a relational framework. In this article we will explore the psychodynamics of self-harm and suicide, focusing on how an understanding of the possible unconscious meanings and functions of these manifestly destructive acts against the self may assist in their assessment and management. The ideas introduced here will be illustrated with brief clinical vignettes, which have been anonymised to preserve confidentiality. A glossary of the psychoanalytic terminology used in this article is provided in Box 1.

\section{The development of the self}

By definition, 'self-harm' refers to an act aimed at the 'self'. But suicide and self-harm are also destructive acts against the body. How are the self and body related, and why would a person choose to damage or destroy either?

Freud proposed that the mind originally develops from the body (Freud 1923). The ego is initially derived from bodily sensations, especially those coming from the surface of the body. As the baby becomes more oriented to the external world, primarily represented by the mother, its ego develops via a gradual process of identification with the goodness of the mother in her provision of care and sustenance, which alleviates painful bodily feelings
Jessica Yakeley is a consultant psychiatrist in forensic psychotherapy, Director of the Portman Clinic, and Director of Medical Education at the Tavistock and Portman NHS Foundation Trust, London. She is also Editor of Psychoanalytic

Psychotherapy and a Fellow of the British Psychoanalytical Society. William Burbridge-James is a consultant psychiatrist in medical psychotherapy in Southend-on-Sea, Essex, and Chair of the Specialty Advisory Committee of the Faculty of Medical Psychotherapy at the Royal College of Psychiatrists, London. Correspondence Dr Jessica Yakeley, Portman Clinic, 8 Fitzjohns Avenue, London NW3 5NA, UK. Email: jyakeley@tavi-port.nhs.uk

\section{Copyright and usage} (C) The Royal College of Psychiatrists 2018.

${ }^{\dagger}$ In the next issue of Advances, Jessica Yakeley will explore psychodynamic approaches to violence. 
B0X 1 Psychoanalytic terminology

Death instinct The innate destructive force underlying human aggression, proposed by Freud (1920), that operates insidiously in opposition to the 'life instinct'.

Ego In Freud's structural model of the mind (Freud 1923), the ego mediates between the conflicting demands of the id, superego and reality. The ego is the executive organ of the psyche, controlling motility, perception and contact with reality, and, via the defence mechanisms located in its unconscious part, the ego modulates the drives coming from the id.

Identification A normal developmental process in which the qualities of another person are internalised and gradually become part of the self, as opposed to the more primitive process of 'introjection', where internal representations still feel like 'other'.

Mentalisation The capacity to reflect and think about one's mental states, including thoughts, beliefs, desires and affects, and to be able to distinguish one's own mental states from those of others.

Object A significant person in the individual's environment, the first object usually being the mother.

Object relation(ships) The individual's mode of relating to the world. Object relations theory, developed by psychoanalytic theorists such as Klein and Winnicott, proposes that the child's experience, perceptions and fantasies about their relationships with significant caregivers become incorporated in the mind at an early stage of development to become prototypical mental constructs that influence their mode of relating to others in adulthood.

Repetition compulsion A manifestation of the death instinct whereby a person's unconscious tendency in adult life is to repeat behaviour associated with past traumatic experiences, in an attempt to resolve feelings of helplessness and conflict (Freud 1920).

such as cold or hunger. Winnicott (1965) and Bion (1970) emphasised the role of the mother's emotional relationship to the infant's body, enabling the infant to contain anxiety or physically painful states via the mother's physical and emotional presence, which is then internalised into the developing ego.

These early psychoanalytic theories of the development of the self from the body were elaborated by Anzieu's idea that the ego was constructed as a 'skin ego' through the baby's early contact with the mother's skin (Anzieu 1974), and Bick's emphasis on the 'holding' function of the skin in demarcating a boundary between what is experienced internally within the body and mind, and what is external (Bick 1968). The early internal physical sensations experienced by the infant are continually modulated by the mother's affective state and love for her child in their close physical exchanges, including touch, gaze, smell and vocalisations, which are gradually integrated to form the developing body image; thus, the earliest sense of self is embedded and mediated through bodily sensations. These psychoanalytic formulations have been substantiated by more recent studies that show the importance of early handling and touch for brain growth, stress and immune function, attachment, the regulation of physiological systems, and the development of cognitive and affective awareness of the body (Lemma 2010).

Attachment theory develops these psychoanalytic ideas further, in proposing that the development of the self occurs through the internalisation of different types of attachment relationship with significant early caregivers, usually the mother, to form 'internal working models' or representations of relationships with these caregivers (Bowlby 1969). A secure sense of self develops in the presence of a loving and understanding primary caregiver who is able to mirror the infant's emotional states, to help the infant make sense of and differentiate its internal and external environment, identify and tolerate affects, regulate impulses, develop the capacity for symbolisation and reflection, and gradually develop a stable sense of integrity.

However, when there is a lack of attunement and sensitive mirroring between mother and infant, or when the child's early experiences are frankly traumatic if parental figures are abusive, depriving or absent, the child internalises pathological attachment relationships and an impaired capacity to represent and regulate feelings. Here, the healthy development of the sense of self has been impeded and is poorly differentiated from internal representations of significant others. In psychoanalytic terms, the child's ego remains fragile and relies on primitive defence mechanisms (Box 2) such as projection, projective identification and splitting to avoid painful feelings. Anxiety-provoking experiences of the infant's body cannot be represented in the mind, but are instead enacted and communicated via the body. Good and bad, self and other, inner and outer reality become confused.

\section{Written on the body - self-harm as communication}

Self-harm and suicide may be understood to be manifestations of disorders of the self; as attempts, albeit pathological, to reinstate the boundary between mind and body, and to communicate and resolve childhood trauma. Freud (1914) proposed that acting out was the substitute for remembering traumatic childhood experiences and was unconsciously aimed at reversing that early trauma. The person is spared the painful early memory of the trauma and, via action, masters the early experience, which was 
originally suffered passively. However, if these early memories and feelings cannot be symbolised or represented in the mind, they remain unconscious and unprocessed and will continue to be expressed in action. This is the essence of what Freud (1920) saw as the repetition compulsion.

Suicide and self-harm may be seen as acts with unconscious meanings, communications that convey in action repressed thoughts, feelings and fantasies that cannot be allowed into consciousness or put into words. Previous traumas involving neglect or abuse of the person's body in infancy or childhood cannot be mentalised and remain trapped in the body. Adshead (2016) describes how in self-harm the body becomes the medium of communication in which a form of mapping or writing on it registers the internal dynamics of relationships with self and others.

\section{The body boundary}

Self-harm involves a breach of the boundary of the body - either the skin in cutting, or through ingestion of medication or poison. The body boundary connects the external with the internal, the mind and the body, and the self and others. The body violation and actual penetration of the skin may be seen as a repetition and unconscious enactment, where the opening up of the skin and flow of blood may communicate an unconscious wish to excise and expunge what is felt to be bad and to rid the person of unbearable thoughts and feelings (Box 3).

Crossing the body boundary may represent a transition: the transition from outside to inside with the ingestion of poisons, from inside to out with the flow of blood, from internal mental life to external reality. The idea of transition suggests that self-harm may be a communication of difficulties faced at points of transition in life and the challenges these pose. These difficulties may be the echo of earlier points of transition in childhood and adolescence related to attachments and ruptures in relationships with significant others. In clinical practice, suicidal patients are at increased risk at points of transition between care-providers, for example following discharge from an emergency department or psychiatric in-patient unit to care in the community (Crawford 2004) (Box 4).

\section{Aggression towards self and others}

Suicide and self-harm are activities that can be understood in relational terms, in which, as described above, early adverse experiences result in internal representations of the self and others that have not been fully differentiated. Freud proposed that suicide resulted from internalised anger that had been originally directed at someone close

\section{BOX 2 Primitive defence mechanisms}

Acting out Expressing an unconscious wish or fantasy through impulsive action as a way of avoiding experiencing painful affects.

Idealisation Experiencing others as perfect to avoid anxiety or negative feelings such as contempt, envy or anger.

Projection Expelling unacceptable aspects of the self and attributing them to someone or something else.

Projective identification Powerful projection of unacceptable aspects of the self to someone else, so that the target of the projection is unconsciously pressurised to behave, think and feel in keeping with what has been projected into them.

Splitting Division or polarization of self and other into good and bad by focusing selectively on their positive or negative attributes to avoid conflict.

to the person. In Mourning and Melancholia (Freud 1917), he describes how mourning is impeded if ambivalence and hostility predominate towards the lost object, and a state of melancholia ensues. The hated object is incorporated within the self, which is then attacked as if it were the object. In other words, underlying suicide and acts of selfdestruction are attacks on the self that is unconsciously identified with someone whom the person has hated and lost.

In children who have been abused, the abuser may be internalised in the psyche as a dangerous figure, yet one with whom there is a deep involvement and from whom it is hard to break free. This is especially complicated if the abuser is someone who was previously trusted and loved, such as a parent. Angry and aggressive feelings towards the abuser are experienced as unacceptable, because the object of these destructive feelings is the very person the child is dependent on for support and care. This creates a psychic dilemma where the child simultaneously perceives and confuses the good object with the bad behaviour. The ensuing

BOX 3 Clinical vignette: violation of the body

Clara, a 23-year-old woman, presented to mental health services with a chronic history of cutting her legs, abdomen and genitals. Inquiry into the motivations of her self-harm revealed that cutting her skin provided an outlet for feelings of revulsion about her body. Clara associated this with being sexually intruded upon in childhood and adolescence by her mother, who insisted on cleaning and 'washing out' Clara's vagina until she was 15 . She felt that her body had been irreversibly damaged and that her insides were a disgusting mess. This internal 'mess' could affect any part of her body: she feared that the dentist would discover revolting decay in her mouth, or that her acne would spread rampantly all over her skin and repel everyone. Piercing her skin and seeing blood oozing from her wounds offered temporary relief by 'washing out' toxic parts of her body. 
BOX 4 Clinical vignette: idealisation, merger and separation

Anne was in her late 30s when she was seen for individual psychotherapy for severe depression. She had taken a serious overdose following the end of a brief relationship that had promised hope. She self-harmed by burning the skin on her arms, which left deep scarring. Anne had been adopted as a baby by a kind and committed couple and she did not know about her biological family.

During the course of therapy her therapist became an idealised parent figure. He felt a deep empathy for her, but felt drawn into this idealised position, which he needed the help of supervision to process. It was as if there was no room for her therapist to be anything other than a perfect 'other' in Anne's mind and in her therapy. Breaks in the therapy became difficult for Anne to bear and the therapist would find that she had burnt herself while he was away. It seemed as if she did not have a good enough internal object that she could turn to, and she had to protect her wished-for idealised absent mothertherapist and turn her hatred on herself for her early loss. As the ending of her therapy drew close, Anne became fraught with anxieties about whether she would survive or kill herself, and she withdrew from therapy and isolated herself at home. It was only with the close involvement of her psychiatric team that she was able to return to therapy and start to process some of her feelings about ending and become more aware of her hostility to her therapist - now recognised as a complex object, neither all good or all bad - for abandoning her. Therapy was ended safely.

unbearable confusion, rage and horror are internalised as parts of the bad self, allowing the child to hold onto a fantasy of the loved and needed object as good. This may result in the child believing that they are to blame for what took place, so that harming their own body may be seen as punishment for any gratification that may have been experienced and to assuage an unconscious sense of guilt.

Self-harm may also be a way of reversing the helplessness and powerlessness experienced in the face of abuse. The child may manage these feelings via passive resistance and dissociation, which, as psychological defences, provide a sense of personal control and power in a situation where these are not possible. However, these coping mechanisms may then become incorporated into the self, becoming a way of being and relating in which the child feels different and distant from others and wary of future relationships. Self-harm may represent the desire to regain control over the abuser; however, the abuser is now part of the self and becomes confused with the victim self, so that the self-destructive act represents an unconscious attack on both perpetrator and victim.

\section{Unconscious fantasies}

Hale describes various fantasies that are expressed by suicidal people (Hale 2008). Over a period of 25 years he interviewed more than 500 individuals who had been admitted following a suicide attempt. These suicidal fantasies, which vary in their level of conscious awareness, elaborate the relationship between the self, the body and significant others in

the person's life. These include what he calls the 'revenge fantasy', the 'assassination fantasy' and the 'merging fantasy'. In the revenge fantasy, the aim is to make others suffer for how they have maltreated the person. In the assassination fantasy, which is more common in those with psychosis, the body is experienced as a source of madness, which must be killed off so that the self survives: the person is therefore acting in self-defence. In the merging fantasy, which Hale believes underpins all other fantasies, the suicidal wish is to merge with an omnipotent mother to attain a state of timeless bliss and to escape the intolerable pain of living. Maltsberger \& Buie (1980) contextualise this regressive suicidal quest in what they describe as the myths of religious beliefs, the collective expression of commonly shared fantasies in which the wish for merger accompanies the fantasy of death as a passage into the new world of infinite peace.

Gardner (2001) also emphasises the fantasy of an omnipotent mother, but one that is experienced as persecutory. In her work with young women who were cutting, Gardner noted how these individuals often described an ambivalence about separation from their mothers. She proposes that their selfharm is based on an unconscious fantasy of being stuck with an overwhelming, malevolent and avaricious maternal figure. She observed in these women's relationship with their mothers an 'intrapsychic struggle characterised by a quality of enslavement and a longing to cut the ties that so tightly bound this relationship' (Gardner 2001: p. 12). She suggests that this psychic conflict stems from the development of early object relationships where the self is captivated and held in thrall by a particular aspect of the mother that threatens complete incorporation. This forms a tyrannical inner object configuration which overwhelms the child and from which there is ambivalence about separation, leading to a desperate oscillation between going towards and away from the malevolent figure. She also observed that the young women appeared to be enthralled in a state of mind that she termed 'encaptive'. This involves a sense of being captivated and intensely involved with the object in an omnipotent pact, and a wish to get away from the object's possession, manifest as withdrawal and aggression turned on the self (Box 5).

\section{Pathways to suicide}

Although for many individuals who self-harm there is no conscious intention to kill themselves, for others the boundary between the acts of self-harm and suicide are not so clear cut. In her paper Addiction to Near Death, Joseph (1982) highlights how compulsive and addictive the urge to self- 
BOX 5 Clinical vignette: confusion of self/other boundaries

Clara (described in Box 3) experienced her relationship with her mother as a confusion of boundaries and lack of differentiation. As an adult, Clara moved to another country to escape her mother and speak a language different from her 'mother tongue', but she felt compelled to telephone her every day. She remembered making an active decision in adolescence to hate her mother, but began to experience suicidal feelings and started to self-harm by cutting. We may conceptualise her mother's sexually intrusive behaviour as interfering with Clara's ability to separate her own body from her mother's body, so that she was unable to internalise a stable body image that could adequately defend her against separation anxiety. Confronted with her developing sexual body at puberty, Clara's previously unconscious hatred of her mother's body became conscious, but Clara remained unconsciously unable to distinguish between her own sexual body and that of her mother's, the hatred became directed at herself, and was enacted in self-harm.

harm may become. This may be due, in part, to the physical release of endorphins following cutting of the skin, but cutting may also hold a significant psychological function for the person. Joseph conceptualises this psychoanalytically as the pull of the individual by the death instinct into a private place of violence, a no man's land between life and death where the person is unreachable by others on the side of the living. Joseph's ideas are pertinent to the current era of the internet, where someone with suicidal thoughts can hide with like-minded individuals in a secret arena in which their fantasies may be rehearsed in virtual reality.

Hale (2008) describes a suicidal fantasy that he calls 'dicing with death', in which the person gambles their life according to fate, assigning responsibility for life to others. Joseph elaborated further the intrapsychic and interpersonal function of this fantasy in emphasising how the destructive part of the mind triumphs over the more healthy part. The person remains trapped in an excited but very dangerous state of omnipotence and destructiveness, in which any feelings of vulnerability and hopelessness are projected into the therapist. When this manic defence breaks down, excitement is replaced with desperation, virtual reality becomes concrete reality, and suicidal thoughts are put into action (Box 6).

In his work with suicidal patients, Hale describes what he observed as a common pathway to suicide in which the person enters into a 'pre-suicidal state' (Ringel 1976) where the suicidal fantasies become more conscious and plans for the suicidal act are

\section{BOX 6 Clinical vignette: addiction to near- death}

William had been referred to drug and alcohol services for alcohol dependence and addiction to benzodiazepines, and was receiving treatment in a relapse prevention group. Although expressing a wish to remain abstinent, William continued to procure diazepam over the internet; he took this in such large doses that the other group members became very worried for his safety. William denied actively wanting to kill himself, but said he was addicted to the feeling of being 'on the edge' - on the border of consciousness and unconsciousness, hovering between life and death. Group sessions became dominated by William's excited accounts of drug-induced euphoria, leaving the other group members not knowing whether they would see him alive at their next meeting. Here we can see that all feelings of despair and helplessness were projected into the other group members, while William remained omnipotent and in control of the group. Only when he was told that he could not remain in the group if he did not address his drug addiction did he admit to seriously planning to kill himself because of the hopelessness of his life, and accepted intervention from the crisis team.

developed. This state of mind is usually triggered by an interpersonal event that the person experiences as a rejection or betrayal, and may last for hours or days. However, at some stage there is a final trigger that precipitates the person into a confusional state in which feelings and thoughts become fragmented. The trigger will vary according to the individual and circumstances, but in Hale's experience usually involves a perceived rejection. The trigger may be as apparently innocuous as a verbal insult, a look or a turning away of the other person, but the suicidal person experiences it as a psychic assault. This pushes the person into a mental state in which the distinction between fantasy and reality becomes blurred and more mature ego defence mechanisms fail, allowing into consciousness unacceptable ideas and feelings that must be expelled immediately by primitive physical defences. The body boundary is now crossed and the suicidal fantasy is translated into physical action. Once this crucial border between mind and body is breached, it becomes easier to discharge intrapsychic tension via a physical pathway, which may be one explanation for the fact that the most important actuarial risk factor for future suicide is previous suicide attempts.

\section{Self-harm as a sign of hope}

In contrast to the devastating aftermath of completed suicides, Motz (2009) suggests that selfharm is fundamentally an attempt to stay alive 
through its communicative aspects and powerful function for the person, and must be clearly distinguished from a suicidal attempt. She draws on Winnicott's (1956) notion of the anti-social tendency as a sign of hope, in that the act of aggression or delinquency, apparently destructive and hopeless, reflects the person's hope that an environment exists that can recognise and meet their needs. She cites Straker (2006), who studied transcripts from people who self-harmed that were often more eloquent than expected if self-harm is solely viewed as an inability to verbalise. Straker proposes that selfharm is more than just a form of communication, but is an act of self-creation and self-identification. She describes cutting as 'signing with a scar', in which self-mutilation is not inferior to words, but may be a more meaningful language for the person who is discovering herself.

Linking to cultural and theological theories of selfharm, Motz (2009) talks of the 'flesh-made word', where self-harm is a transformational act anchored in cultural and religious practices that signify the presence of other unseen aspects of the self which are made explicit through scarring. This is linked to the work of Favazza (1996), who, through his study of the cultural significance of scarification, proposes that the scars resulting from self-mutilation have symbolic meaning relating to notions of rebirth, continuity of life and stability of relationships. Favazza describes self-harm as the deliberate destruction of one's body tissue without conscious suicidal intent. Self-injury is understood as a morbid form of self-help, temporarily alleviating distressing symptoms, and attempting to heal, to attain some measure of spirituality and to establish a sense of personal order.

\section{The role of countertransference in the assessment and management of self-harm and suicide attempts}

Many patients who self-harm or have suicidal thoughts are treated with a lack of empathy, and even hostility, by healthcare professionals. Patients may feel that more importance is paid to their physical health, rather than their mental state (Cole-King 2013). Self-harm is often viewed as deliberately 'attention-seeking', which is seen as a negative behaviour that should be discouraged. However, people who self-harm may indeed be seeking attention, but their attention-seeking is a plea for compassion and understanding of the unconscious communications in which action has taken the place of words.

The immediate aftermath of a suicide attempt or act of serious self-harm may be a window in which the underlying fantasies that fuel the person's self-destructive ideation and behaviour can be accessed. Managing the patient's acute risk is, of course, the primary task; but following self-harm the patient's psychological defences are weaker and the patient may be more conscious of the underlying triggers, beliefs and emotions that preceded the act. This is therefore an important time for the clinician to assess the patient's mental state - not only to ascertain on-going risk, but to gain understanding of more unconscious motivations before these are lost from sight as the patient becomes more defended.

The clinician's countertransference is a tool through which the patient's internal world may be accessed (Box 7). Countertransference refers to the therapist's thoughts, feelings and responses to the patient, which reflect the patient's unconscious mental states. Countertransference may be understood as an unconscious communicative process in which the patient uses primitive defence mechanisms, such as projection and projective identification, to rid themselves of affects and object relationships that they cannot recognise as internal to themselves, by projecting and attributing them to others. Countertransference is seen as a source of useful information about the patient, in that the therapist's response to the patient may reflect how other people respond to the patient, thus providing information about the patient's internal object relationships.

\section{Containment versus acting out}

For people who self-harm or are suicidal, the clinician may become the unwitting recipient of the patient's unwanted feelings. Feelings of aggression, hatred, hopelessness, desolation, anguish and despair are expelled through self-violence or projected into those around them. These are paradoxically often the people who are trying to help

\section{BOX 7 Countertransference}

- Countertransference refers to the thoughts, feelings and emotional reactions that the therapist/clinician has towards the patient

- It is an unconscious process that the therapist may not be fully aware of

- It arises from the projections of the patient's unwanted thoughts and feelings, as well as unresolved conflicts, into the therapist

- It provides information about the patient's expectations of relationships

- Awareness of, and reflection on, countertransference allows the clinician to act more thoughtfully towards the patient, rather than making unthinking and sometimes unhelpful responses 
them, as any care is experienced as untrustworthy and dangerous and must therefore be killed off. The dilemma facing the healthcare professional is to accept the self-harm while enabling the patient to gradually recognise and own their aggression towards themselves and others. This means that the clinician must receive and contain thoughts, feelings and conflicts that the patient cannot tolerate, understand their unconscious meaning and communicate this back to the patient in a form that the patient can bear, enabling the patient to gradually comprehend and verbalise emotions, experiences and memories that were felt to be unbearable. The therapist is unconsciously asked to perform the dual role of retaining hope while surviving the patient's hostility and aggression. This is often not easy as the professional's own unconscious conflicts - of faith and faithlessness, of love and hatred, of loneliness and longing - may become entangled with those projected by the patient, which may result in confusion and re-enactments. Here, the professional who has been invested with the patient's unwanted aspects may unconsciously identify with what has been projected into them and be unconsciously pressurised by the patient to act out in unhelpful and sometimes destructive ways, thus mirroring the patient's self-destructiveness (Box 8). The importance of clinical supervision and other facilitative spaces for clinicians and other professionals involved in the care of people who self-harm or are suicidal to reflect on their responses, acknowledge and process negative feelings, and understand their meanings must not be underestimated.

\section{Psychodynamic psychotherapy for self- harming and suicidal patients}

Although there is some evidence showing the efficacy of psychological interventions in reducing the repetition of self-harm episodes compared with routine care, the evidence base is hampered by uncertainty and heterogeneity with respect to the population studied, treatment length, therapeutic modality and setting, which lower the quality of the evidence (National Collaborating Centre for Mental Health 2012). A recent Cochrane review of psychosocial interventions for self-harm in adults (Hawton 2016) showed that psychological interventions based on cognitive-behavioural therapy (CBT) can result in fewer individuals repeating self-harm, although the quality of this evidence ranged from moderate to low. The review also found that dialectical behaviour therapy for people with multiple episodes of self-harm or probable personality disorder may lead to a reduction in
BOX 8 Clinical vignette: an enactment of countertransference
Dr S, a core trainee in psychiatry, while on call at night, was asked by the nursing staff to see a patient on the ward who had a diagnosis of emotionally unstable personality disorder and a history of severe self-cutting, and who was expressing suicidal ideation. However, when Dr S interviewed the patient she denied feeling suicidal and said that the nurses were always interfering and exaggerating things. The nurses insisted that half an hour earlier the patient had expressed a wish to die, and said they were concerned as they felt she had been making progress. Dr S found herself, by contrast, feeling annoyed and resentful and wondered why a patient with a primary diagnosis of personality disorder had been admitted as an in-patient. She told the nurses they were wasting her time, and abruptly interrupted the patient's discourse, saying that she was clearly fine. During discussion of this patient in the Balint group for core trainees run by a consultant medical psychotherapist, Dr S realised that the patient was unconsciously splitting the staff looking after her. Dr S's negative countertransferential feelings reflected the patient's destructive feelings, which the patient disowned and projected into Dr S.

The patient was also experiencing as intolerable any hopeful feelings reflecting progress and this was projected into the nursing staff, whose care she denigrated. Unable at the time to reflect on her affective state, Dr S had instead acted out by chastising the nurses and 'cutting off' the patient, mirroring the patient's 'cutting out' of intolerable states of mind that she could only communicate by cutting her body. the frequency of self-harm, but this finding was based on low-quality evidence. Other therapeutic approaches were mostly evaluated in single trials of moderate to very low quality and therefore the evidence relating to these interventions was inconclusive.

However, there is a growing body of empirical evidence from high-quality outcome studies to show that psychodynamic psychotherapy is as effective as psychological interventions such as CBT in the treatment of a range of mental disorders (Shedler 2010; Driessen 2013; Yakeley 2014). This includes recent evidence of the effectiveness of psychodynamic psychotherapy in patients with treatmentresistant depression, a population in which the rate of suicide attempts and completed suicides is significant (Fonagy 2015).

Psychodynamic psychotherapy is just one of several psychodynamically informed therapeutic interventions potentially available to psychiatrists to assist in the overall treatment of suicidal and selfharming patients, and we are not advocating that all such patients should be referred for specialist psychotherapy. However, a psychodynamic understanding of the patient's unconscious mental processes and motivations may guide clinical encounters and interpersonal exchanges between patient and clinician, and contribute to the development of effectual multimodal and multidisciplinary approaches to the complexities and challenges that psychiatrists face in their work with patients at risk of self-harm and suicide. 
MCO answers

$1 d \quad 2$ a 3 e $4 d \quad 5 e$

\section{Conclusions}

Dealing with patients who self-harm or are suicidal is a routine part of the clinical practice of many psychiatrists and other mental health professionals. Effective risk assessment and management is rightly focused on the patient's manifest mental state, and past and present behaviours. However, attention to the patient's unconscious fantasies, feelings and motivations may yield additional valuable information that can contribute to a formulation of how their difficulties and historical antecedents culminate in acts of aggression towards the self. Although the clinician should strive to be compassionate, collaborative and hopeful, it is also important to recognise the patient's more negative and destructive feelings, and to carry these for the patient until that individual is able to allow them into conscious awareness. Situating the patient's motivations and actions within a relational framework, in which the psychodynamics of the patient's past and present experiences with self and others are explored within the safety of the therapeutic relationship, may facilitate emotional contact with the patient, allow them to think unthinkable thoughts and feel unmanageable feelings, thereby lessening the grip of self-destructive impulses and actions.

\section{References}

Adshead G (2016) Written on the body: deliberate selfharm and violence. In A Practical Guide to Forensic Psychotherapy (eds Weldon E, Van Velsen C): 110-114. Jessica Kingsley publishers.

Anzieu D (1974) Le Moi-peau. Nouvelle Revue Psychoanalyse, 9: 195-208 (English translation (1980): Skin ego. In Psychoanalysis in France (eds S Lebovici, D Widlocher). International Universities Press.

Bick E (1968) The experience of the skin in early object relations. International Journal of Psychoanalysis, 49: 558-66.

Bion WR (1970) Attention and Interpretation. Karnac.

Blasco-Fontecilla H, Oquendo MA (2016) Biomarkers of suicide: predicting the predictable? In Understanding Suicide: From Diagnosis to Personalized treatment (ed Courtet P): 77-83. Springer International Publishing.

Bowlby J (1969) Attachment and Loss. Basic Books.

Cole-King A, Parker V, Williams H, et al (2013) Suicide prevention: are we doing enough? Advances in Psychiatric Treatment, 19: 284-91.

Cover $R$ (2016) Suicides of the marginalised: cultural approaches to suicide, minorities and relationality. Cultural Studies Review, 22: 90-113.

Crawford MJ (2004) Suicide following discharge from in-patient psychiatric care. Advances in Psychiatric Treatment, 10: 434-8.

Driessen E, Van HL, Don FJ, et al (2013) The efficacy of cognitive behavioral therapy and psychodynamic therapy in the outpatient treatment of major depression: a randomized clinical trial. American Journal of Psychiatry, 170: 1041-50.
Durkheim E (1897) Le Suicide: Etude de Sociologie. Alcon.

Favazza AR (1996) Bodies Under Siege: Self-Mutilation and Body Modification in Culture and Psychiatry. John Hopkins University Press.

Fonagy P, Rost F, Carlyle J (2015) Pragmatic randomized controlled trial of long-term psychoanalytic psychotherapy for treatment resistant depression: the Tavistock Adult Depression Study (TADS). World Psychiatry, 14: $312-21$.

Freud S (1914) Remembering, repeating and working through. In The Standard Edition of the Complete Psychological Works of Sigmund Freud (vol. 12) (ed Strachey J): 145-56. Hogarth Press.

Freud S (1917) Mourning and melancholia. In The Standard Edition of the Complete Psychological Works of Sigmund Freud (vol. 12) (ed Strachey J): 243-58. Hogarth Press.

Freud S (1920) Beyond the pleasure principle. In The Standard Edition of the Complete Psychological Works of Sigmund Freud (vol. 18) (ed Strachey J): 1-64. Hogarth Press.

Freud S (1923) The ego and the id. In The Standard Edition of the Complete Psychological Works of Sigmund Freud (vol. 19) (ed Strachey J): 13-27. Hogarth Press.

Gardner F (2001) Self-Harm: A Psychotherapeutic Approach. BrunnerRoutledge.

Hale R (2008) Psychoanalysis and suicide: process and typology. In Relating to Self-Harm and Suicide (eds Briggs S, Lemma A, Crouch W): 13-24. Routledge.

Hawton K, Witt KG, Taylor Salisbury TL, et al (2016) Psychosocial interventions for self-harm in adults. Cochrane Database of Systematic Reviews, 5: CD012189 (doi: 10.1002/14651858.CD012189).

Joseph B (1982) Addiction to near death. International Journal of Psychoanalysis 63: 449-56.

Kelly C, Dale E (2011) Ethical perspectives on suicide and suicide prevention. Advances in Psychiatric Treatment, 17: 214-19.

Lemma A (2010) Under the Skin: A Psychoanalytic Study of Body Modification. Routledge.

Maltsberger JT, Buie DH (1980) The devices of suicide: revenge, riddance and rebirth. International Review of Psycho-Analysis, 7: 61-72.

Motz A (2009) Self-harm as a sign of hope. In Managing Self-Harm, Psychological Perspectives (ed Motz A): 15-41. Routledge.

National Collaborating Centre for Mental Health (2012) Self-Harm: The NICE Guideline on Longer-Term Management (National Clinical Guideline Number 133). British Psychological Society and Royal College of Psychiatrists.

Ringel E (1976) The pre-suicidal syndrome. Suicide and Life Threatening Behaviour, 6: 131-40.

Shedler J (2010) The efficacy of psychodynamic psychotherapy. American Psychologist, 65: 98-109.

Straker G (2006) Signing with a scar: understanding self-harm. Psychoanalytic Dialogues, 16: 93-112.

Taylor JD, Ibañez LM (2015) Sociological approaches to self-injury. Sociology Compass, 9: 1005-14.

Winnicott DW (1956) The anti-social tendency. Reprinted (1975) in Through Paediatrics to Psycho-Analysis: Collected Papers (DW Winnicott): 306-15. Basic Books.

Winnicott DW (1965) The Maturational Processes and the Facilitating Environment. International Universities Press.

Yakeley J (2014) Psychodynamic psychotherapy: developing the evidence base. Advances in Psychiatric Treatment, 20: 269-279. 
MCOs

Select the single best option for each question stem

1 In the development of the self:

a Freud proposed that the body image develops from the ego

b early psychoanalytic theories have not been substantiated by recent neurobiological studies

c the 'skin ego' demarcates the ego from the id

d one effect of traumatic experiences may be lack of differentiation between internal representations of self and others

e self-harm may represent the bodily enactment of symbolised experiences.

\section{Acting out:}

a may be a manifestation of the repetition compulsion

b represents symbolic thinking

c may be a substitute for forgetting

d embodies processed traumatic experiences

$\mathrm{e}$ is a mature defence mechanism.

\section{Self-harm:}

$\mathrm{a}$ in psychodynamic terms equates with a suicidal act

b is always an unconscious communication for help

c is often a manipulative behaviour

d always involves projective identification

e always involves a relationship, whether consciously or unconsciously.
4 Unconscious fantasies:

a differ between self-harm and suicide

b may only be understood in psychotherapy

c are always based on lived experience

d may be linked to difficulties in separation from primary caregivers

e when triggered, always translate into physical action.

5 Countertransference:

$\mathrm{a}$ is a negative phenomenon

$\mathrm{b}$ is the opposite of transference

c is always caused by the patient's projections

d only relates to the relationship between patient and clinician

e may provide understanding of the patient's internal object relationships. 